\title{
EL CARMEN EPIGRAPHICUM DE SANTA EULALIA DE BÓVEDA (LUGO) Y LOS LOCI SIMILES VIRGILIANOS: UNA APORTACIÓN AL CIL XVIII/2 ${ }^{1}$
}

\author{
The carmen epigraphicum of Santa Eulalia de Bóveda (Lugo) \\ and the Virgilian loci similes: a contribution to the CIL XVIII/2
}

\author{
Enrique Jorge Montenegro Rúa
}

Recibido el 7 de diciembre de 2010. Aceptado el 13 de febrero de 2011

Resumen. El autor realiza una revisión de la inscripción poética latina poco conocida de Santa Eulalia de Bóveda (Lugo). Se propone una nueva lectura en la que se tratan cuestiones como el análisis epigráfico, su cronología y la transliteración de la antroponimia griega. Además, se identifican impedimentos para continuar incluyendo la inscripción latina entre los loci similes virgilianos.

Palabras clave:Epigrafía latina, carmina epigraphica, loci similes virgilianos, antroponimia griega, Santa Eulalia de Bóveda.

Abstract. The author revises the little-known Latin poetic inscription of Santa Eulalia de Bóveda (Lugo). A new reading is proposed which addresses issues such as epigraphic analysis, chronology and the transliteration of the Greek anthroponymy. It also identifies some impediments to continue including the Latin inscription among the Virgilian loci similes.

Key Words: Latin epigraphy, carmina epigraphica, Virgilian loci similes, Greek anthroponymy, Santa Eulalia de Bóveda.

\section{INTRODUCCIÓN}

El monumento de Santa Eulalia de Bóveda cuenta con dos vestigios epigráficos. Uno, descubierto durante las primeras actuaciones arqueológicas, se localizó formando parte de la cimentación de un muro situado a pocos metros de la fachada del monumento. Consiste en un fragmento de la parte superior de un ara que presenta la inscripción pro/sa[lute] (López-Martí 1934: 28; HAntEp 312; IRG-II 26; IRPLu 74) siendo identificado desde el inicio como exvoto de curación que coadyuvaría a vincular el yacimiento arqueológico como un ninfeo o centro salutífero (Gómez-Moreno 1949: 422; Chamoso 1952: 246-251)
Durante los trabajos de restauración y conservación dirigidos por M. Chamoso y desarrollados por los arquitectos $\mathrm{L}$. Menéndez-Pidal y F. Pons-Sorolla en los años cincuenta y sesenta se descubrió una nueva inscripción, más completa que la primera, pero cuyos restos de grafía no permiten una cómoda interpretación (fig. 1).

Las vicisitudes de su descubrimiento y la inadecuada manipulación y custodia de los fragmentos ocasionaron pérdidas irreparables que, como era lógico esperar, han repercutido negativamente en su estudio ${ }^{4}$. Sobre esta malograda inscripción versa este artículo.

\footnotetext{
Este trabajo ha sido desarrollado en el marco del proyecto de investigación Formación y disolución de civitates en el NO peninsular. Estructuras de poblamiento y territorio (Civitas). Financiado por el Ministerio de Ciencia e Innovación (HAR-2008-06018-C03-03-HIST.) su investigadora principal es la Dra. Carmen Fernández Ochoa.

Doctorando de la Universidad Autónoma de Madrid. Correo electrónico: montenegro_rua@yahoo.es.

3 Para más información sobre esta y otras corrientes interpretativas relativas a la funcionalidad del monumento (Montenegro Rúa 2008: 26-36).

4 Sólo se conservan dos de sus fragmentos. Desgraciadamente en el mármol de la inscripción también se ha reflejado buena parte de la mala práctica aplicada en el monumento de Santa Eulalia de Bóveda (Montenegro Rúa 2005).
} 


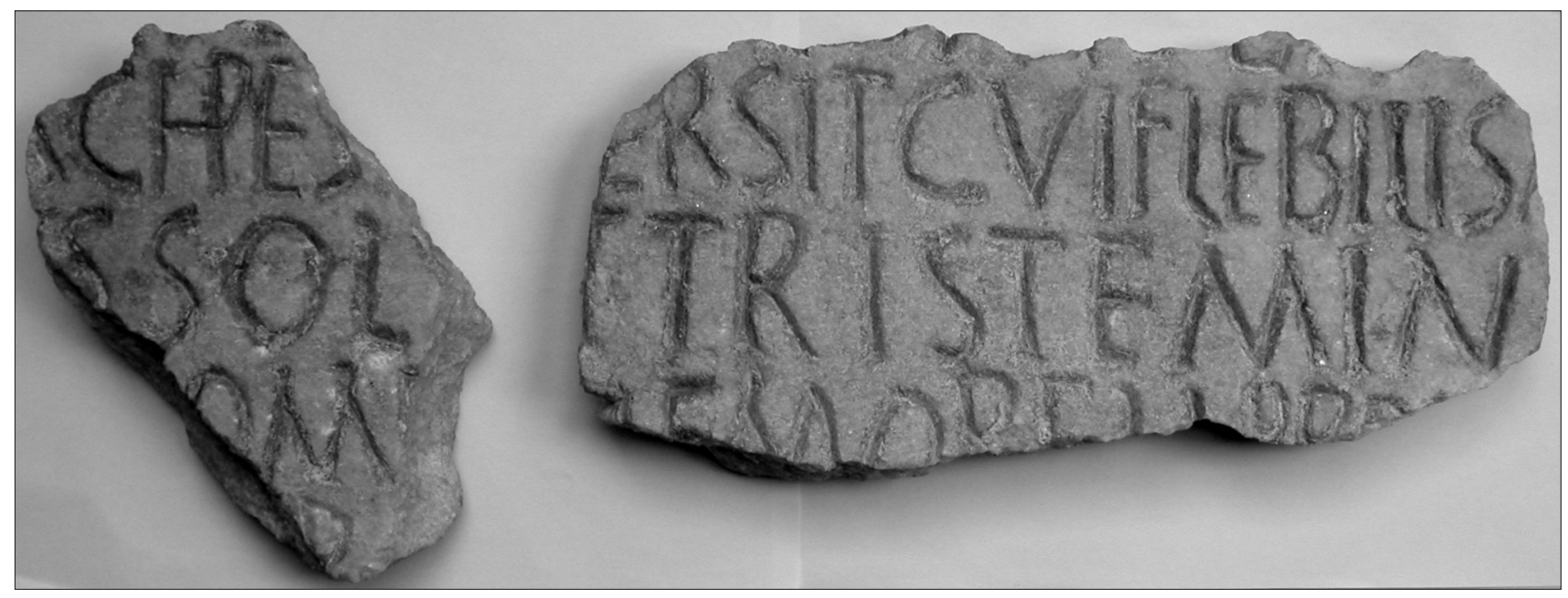

FIGURA 1. Dos únicos fragmentos conservados de la inscripción localizada en los años cincuenta mientras se realizaban trabajos de restauración en Santa Eulalia de Bóveda. N. ${ }^{\circ}$ Inv. Epi-73, Museo Provincial de Lugo (foto del autor).

\section{ESTADO DE LA CUESTIÓN}

F. Vázquez y S. Mariner publicaron las primeras pero someras reseñas (Vázquez Saco 1958-1959: 272-273; Mariner 1960: 326). En el caso del primero todo parece afirmar que no tuvo acceso al material original puesto que no realiza una correcta transcripción ${ }^{5}$; la identifica como lápida sepulcral. El segundo señala la importancia de ser la única inscripción poética de la Gallaecia y en la que observa influencia de Virgilio en la expresión triste ministerium al igual que cuando en la Eneida relata el cumplimiento del rito funerario de la cremación ${ }^{6}$.

En ambos casos observan un nexo HP en el que S. Mariner interpreta como nexo $\mathrm{HR}^{7}$ formando parte de un nombre griego: Chpes[imus].

Inicialmente, S. Mariner atribuye al posible origen oriental la singularidad de esta reminiscencia virgiliana en el ámbito galaico. Sin embargo, años más tarde matiza la importancia de esta muestra epigráfica por lo que supone como credencial de la penetrante latinización que debió experimentar el noroeste peninsular (Mariner 1989: 334).

Lamentablemente, la incorrecta manipulación de los fragmentos y la ausencia de documentación del descubrimiento de la lápida han jugado en contra en la investigación de tan singular vestigio. N. Ares (1963: 179-180) nos describe alguna de las vicisitudes de su hallazgo:

"Hace pocos años, al efectuar la restauración y nuevas exploraciones en nuestro monumento, entre la piscina y el ábside se hallaba en el suelo una delgada lápida de mármol, apenas perceptible a simple vista y de cuya exis- tencia nadie sospechó, hasta que un obrero dejó caer sobre ella una piedra que la hizo saltar en pedazos, descubriendo así una inscripción, que estaba con sus letras de $5 \mathrm{cms}$. grabadas en rojo, vueltas hacia el suelo y pegada a él por esta cara con una dura capa de cal.

Medía aproximadamente unos $75 \mathrm{~cm}$ de largo, por unos 20 de alto; y su grosor de unos $3 \mathrm{~cm}$ en disminución le daba un aspecto de cuña, detalle este muy interesante que tuvimos en cuenta para su lectura, al intentar la colocación de los dos trozos, únicos que se conservan, enlazándolos de modo que se correspondiesen sus renglones en número de cinco».

Otro aspecto a tener en cuenta a la hora de valorar la importancia del artículo de N. Ares al conocimiento de esta inscripción es la publicación de un dibujo realizado sobre los calcos de los dos fragmentos (fig. 2). Sin embargo, también se ha de lamentar que a lo largo de todos estos años no hayan sido tenidos en cuenta, en su justa medida, por los distintos epigrafistas que han estudiado la inscripción ${ }^{8}$.

N. Ares se ciñe estrictamente a lo identificado en los rasgos grabados y a su certera transcripción para ofrecer una interpretación necesariamente condicionada por la escasez del texto y lo inconexo de los restos conservados. A pesar de todo, logra contribuir con una primera lectura que comprende la concatenación de los dos fragmentos:

\section{[--hi]rci-pes mersit cui flebilis m[orbus] \\ [--d] issolv [i]t triste min[isterium] \\ [--c]omi!tia]!e more !!ppo[rum--]}

${ }^{5}$ Además de omitir letras obvias, del rastro more apunta un amore, cuando en vez de una A (letra del todo imposible) se encuentra una E de rasgos muy similar que la del final de esta palabra.

${ }^{6}$ En su artículo, S. Mariner incluye inscripciones en verso de influencia virgiliana no contempladas en la entonces reciente tesis de R. P. Hoogma sobre los influjos de la obra de Virgilio en la poesía epigráfica latina (Hoogma 1959).

${ }^{7}$ A diferencia de la grafía griega, el nexo HP no existe en la grafía latina. S. Mariner lo atribuye a un error del lapicida.

8 Una de las razones de esta omisión puede ser debida a que las aportaciones iniciales efectuadas por N. Ares (1962: 115 n. 2 y 1963: 179-182) hayan sido incluidas en artículos cuyo contenido primordial no era el epigráfico. 

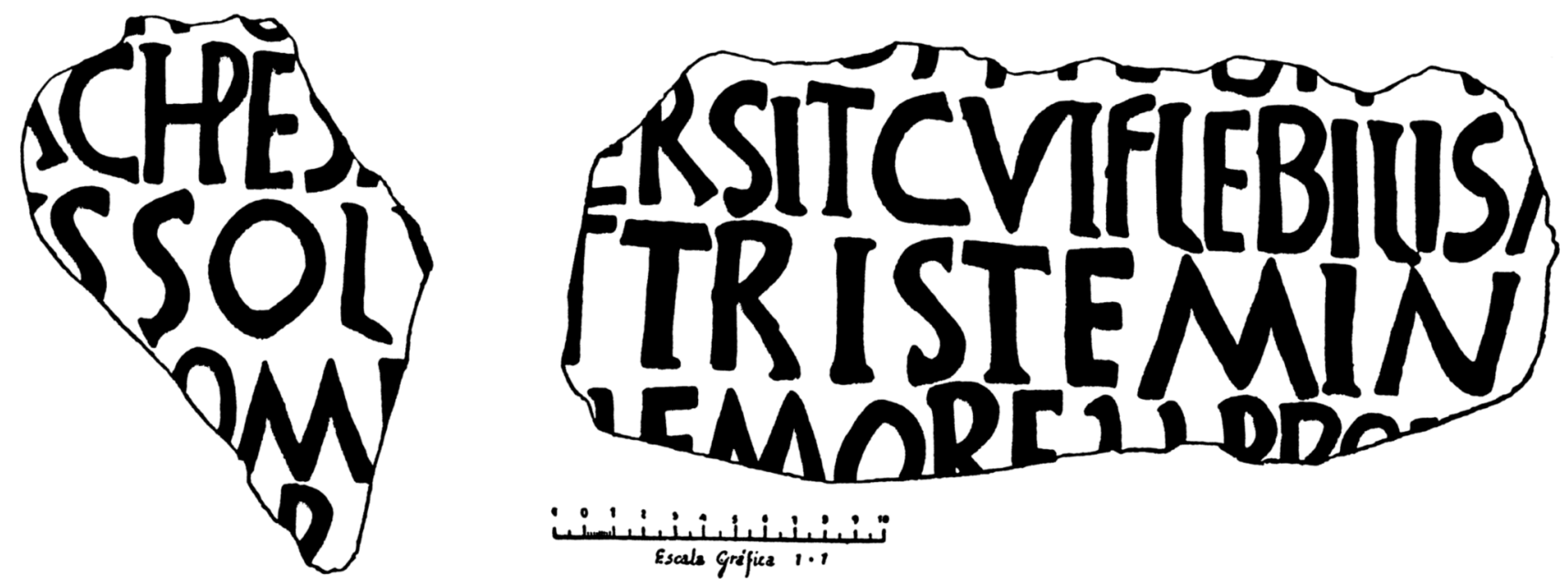

FIGURA 2. Dibujo de los fragmentos a partir de un calco realizado por N. Ares tras su descubrimiento (Ares 1963: lám. 1).

Uno de los aspectos más significativos de su lectura es la de no tener en cuenta el nexo HP e interpretarlo como IP que formaría parte de la palabra hirqui-pes y que aludiria al personaje del sátiro.

Los entronques que observa no serian exclusivamente virgilianos. Su interpretación se basa, además, en indicios de vínculo entre un poema de Ovidio en "Amores», de Luciano en su "Tragopodagra" o en una de las "Epístolas» de Séneca en los que, conceptos y términos afines a la inscripción, narran diversos aspectos de la enfermedad de la gota, vinculado así su temática con la cuestión de Santa Eulalia de Bóveda como centro salutífero en sus orígenes. Esta interpretación complementa sus estudios de las fuentes de la literatura clásica de donde extrae testimonios que aportan cierta claridad sobre el mundo simbólico presente en la decoración de Santa Eulalia de Bóveda, especialmente en los bajorrelieves del vestíbulo (Ares 1962; 1963: 175-179; 1964).

En la obra de F. Arias et al. de 1979 «Inscriptions romaines de la province de Lugo" (= IRPLu 88) se alude a lo limitado del texto para no ser categórico con el carácter poético de la inscripción. Además, la diferencia constatada del espesor en ambos fragmentos junto con una variante de la letra $M$ les permiten justificar que nos encontrariamos ante dos inscripciones diferentes.

Del mayor de los fragmentos ofrecen la siguiente lectura: [pu]ẹr sit cui flebilis [aliquid / ne] triste min[etur-- / --].

Se incide especialmente sobre la presencia de los términos flebilis y triste para atribuirle una clara vinculación con la epigrafía funeraria. Por su parte el texto rememora un tema tan característicamente epicúreo como aquel que evo- caria la fragilidad del hombre, desde su más tierna infancia, ante la amenazante muerte.

Ante esta obra, N. Ares (1984: 120-121) reconocerá que la presencia de las palabras flebilis y triste avala el carácter funerario del epigrama pero, en cambio, no está de acuerdo en que nos encontremos ante dos inscripciones distintas:

\begin{abstract}
".... Lo que no se puede en modo alguno admitir, ni siquiera como sospecha, es que los dos trozos hoy conservados correspondan a dos inscripciones diferentes. Y lo digo con toda seguridad, porque recuerdo la forma apaisada y rectangular de esta lápida antes de ser destrozada e incluso el negativo que dejaron plasmado sus letras en la cal con la que estaba pegada al suelo del monumento. Como, por otra parte, el grosor de los trozos se va adelgazando en forma de cuña, tampoco se puede dudar de la disposición de los mismos, aunque no asi de sus líneas, las cuales eran cinco por lo menos".
\end{abstract}

En 1985 P. Cugusi publica el libro "Aspetti letterari dei Carmina Latina Epigraphican donde, en un pormenorizado estudio, se analizan las repercusiones de los autores clásicos en la producción métrica epigráfica latina.

A P. Cugusi le consta el artículo de S. Mariner sobre loci similes virgilianos ausentes en la obra de R. P. Hoogma (Cugusi 1985: 173; vd. supra y n. 6) pero omite la inscripción lucense en su repertorio. No será hasta 1996, al publicar una segunda edición actualizada con una importante serie de nuevas aportaciones, cuando realice una primera aproximación al análisis de la lápida descubierta en Santa Eulalia de Bóveda (Cugusi 19962: 355) ${ }^{9}$. Refuerza el carácter funerario de la inscripción identificando otra reminiscencia literaria

Es muy probable que la incorporación de la inscripción de Santa Eulalia de Bóveda en esta obra haya sido consecuencia de la publicación de la primera sistematización de CLE Hispaniae, concretamente la parts IV correspondiente al convento juridico Tarraconensis (Gómez Pallarès, 1995), para su incorporación en el futuro volumen XVIII del Corpus Inscriptionum Latinarum, ideado especificamente para las inscripciones latinas en verso (Krummrey, 1964). Tras un aparente olvido se ha relanzado el proyecto ideado en los años sesenta. En el caso de la provincia de Hispania ya han comenzado los trabajos para esta importante recopilación y revisión de la poesía epigráfica latina. El equipo de redacción del fascículo 2 correspondiente está siendo coordinado por J. Gómez. 
virgiliana que le permite restituir [acerbo funere m] ersit cvi flebilis inspirado en el verso $\mathrm{VI}, 429$ de la Eneida (que el mismo Virgilio repite en $\mathrm{XI}, 28$ ) abstulit atra dies et funere mersit acerbo, como igualmente se constatan en otros cármenes epigráficos (Cugusi 1996²: 178-179, 354-355).

En su producción investigadora reciente de los CLE, $P$. Cugusi está centrado en la correcta identificación como carmen de un registro epigráfico cualquiera. Al igual que P. Colafrancesco y M. Massaro, señala el término flebilis como posible evidencia de tal propiedad y menciona la inscripción de Bóveda entre las concordancias existentes (Colafrancesco y Massaro 1986: 270; Cugusi 2007: 60).

Por lo visto hasta ahora, no es de extrañar que R. Hernández incluya la inscripción de Bóveda en su tesis doctoral sobre la poesía epigráfica sepulcral de la Hispania romana en la que se analizan y sistematizan las diferentes formulaciones de los tópicos funerarios dentro del ambiente cultural y religioso pagano (Hernández Pérez 2001).

Al igual que P. Cugusi, vincula la secuencia de la inscripción lucense ersitcuiflebilis con el verso virgiliano más imitado (Aen. VI, 429 y XI, 28) pero por lo fragmentado del texto sólo puede atribuirlo a una adaptación de la que solamente restituye mersit. Avalado también al interpretar el sintagma triste ministerium y el ablativo more, en líneas sucesivas, porque están presentes en otro verso de la Eneida: triste ministerium, et subiectam more parentum (Aen. VI, 223), expresión a modo de lamento del último cumplimiento para con el difunto.

La datación sería tardía, siglos III-IV al igual que el resto de entronques similares localizados en la península itálica (Hernández Pérez 2001: 20).

Sobre esta posible adaptación, J. del Hoyo (2002: 144145) realiza una pronta observación en su interesante aportación al conocimiento sobre las características formales de la poesía latina epigráfica en Hispania:

"Conjeturar y restituir a partir de soportes no vistos es como caminar en medio de la niebla. El editor intuye el camino y puede llegar a su destino, pero también puede extraviarse. Uno puede conocer muy bien a los poetas latinos, incluso el corpus de carmina epigraphica $y$, sin embargo, desviarse en la resolución de una laguna, porque el poeta anónimo se inspira, pero no copia literalmente. Un caso claro es el IRPLu 88a de Santa Eulalia de Bóveda (Lugo), fragmento de placa en que tras un triste min[isterivm] en I. 2 conservada, secuencia que evoca a Virgilio (Aen. VI, 223) en un pasaje en que se describen las exequias de $\mathrm{Mi}-$ seno, en I. 3 se lee more, que los filólogos se han apresurado a completar como more [parentvm], restitución que se correspondería con el siguiente verso virgiliano (Aen. V, 224). Asi Mariner (1960: 224) y Hernández (2001: 19) en- tre otros, pero el fragmento nos ha dejado restos de letras que imposibilitan una lectura parentvm, más bien un pro [...]. Así pues, el poeta se inspira, pero no copia».

Una observación sobre la evocación poética bastante sensata y sobre la que me atrevería a conjeturar que los autores aludidos mostrarian su plena adhesión; excepto, -claro está en lo comentado anteriormente- en el hecho de que hayan restituido la inscripción con more parentum; cuestión sobre la que incide de nuevo en otro artículo (Hoyo 2005: 881).

De igual forma, nada tiene que objetar a la restitución de [--m]ersit de P. Cugusi y R. Hernández en contraposición a [--pu]er sit (IRPLu 88), cuando esgrime el epígrafe de Santa Eulalia de Bóveda como paradigma de la problemática que puede llegar a plantear la scriptio continua - una de las características formales de los CLE Hispaniae- en las inscripciones fragmentarias (Hoyo 2002: 148).

Atención especial merece la comunicación presentada por J. del Hoyo en el XI Congreso Español de Estudios Clásicos celebrado en 2003 en Santiago de Compostela sobre los CLE del noroeste hispánico (Hoyo 2005). De interés ya no sólo porque realiza un estudio específico de la inscripción, que junto con la circunscrita en el gran disco de mármol del denominado Crismón de Quiroga, también de la provincia de Lugo, son los únicos ejemplares de todo el noroeste-, sino por la repercusión de sus conclusiones ya que están consideradas para ser incluidas en el futuro CIL XVIII/2 y que, de hecho, su propuesta de transcripción ya consta como referencia en las bases de datos epigráficas ${ }^{10}$.

Tras examinar la pieza, el análisis paleográfico revalida lo indicado por N. Ares en relación a que los dos fragmentos pertenecen a una misma inscripción cuya transcripción, salvando los problemas inherentes a la scriptio continua, sería la siguiente según extraigo de sus conclusiones:

$$
\begin{aligned}
& \text { [--]ṃọbị!?[--] } \\
& \text { [--]ạc ĥhpes+[c.6 m]ersit cui flebilis ạ [--] } \\
& \text { [patr]ẹs solu [erun]t triste minị[sterium] } \\
& \text { [--]om+[c.5]ṃe morẹ m? prọ[--] } \\
& \text { [--]p[--] }
\end{aligned}
$$

De esta transcripción cabe resaltar que entre las posibilidades atribuibles al nexo HP, dado que esta secuencia de letras no se da en latín, opta por ser el resultado de intercambiar las letras del incómodo nexo $\mathrm{PH}$, sabiendo que el lector no podría equivocarse en su lectura. Propone su ubicación al inicio de la palabra, al igual que muchos términos heredados del griego, lo que obliga a interpretar como perteneciente a la letra $A$ al rasgo que se encuentra al principio de la línea.

${ }^{10}$ Concretamente la de Hispania Epigraphica <http://www.eda-bea.es> que acepta su interpretación (HEp 12, 342). A esta base de datos están interconectadas otras como es el caso de la Epigraphik-Datenbank Clauss-Slaby $<$ http://www.manfredclauss.de $>$. Además, así consta en la incipiente base de datos epigráfica del proyecto CIL XVIII/2 <http://clasica10.us.es:81/inscripciones>. 
En el segundo fragmento, a pesar de que las dificultades paleográficas desaconsejarian su lectura, restituye memorem en la última línea porque "desde el punto de vista del contenido resolvería muchos problemas de interpretación” (Hoyo, 2005: 880 n. 5).

Al igual que R. Hernández le atribuye una datación tardía lo que le permite sustituir el hipotético término parentes por patres. Además, al encontrarse la conexión solvere con triste ministerium en dos de las otras tres inscripciones que contienen el sintagma virgiliano le permite situar ambos fragmentos en el conjunto de la placa.

A. Rodríguez retoma el tema de las aguas salutiferas, pero enmarcado desde el punto de vista espiritual al relacionar la inscripción con una hipotética fase paleocristiana del monumento en la que el estanque se utilizaría como piscina bautismal.

Para vincular la lápida con el mundo cristiano se apoya fundamentalmente en la identificación del nombre de Cristo en el fragmento pequeño con la denominación Chrestus, que localiza en escritores paganos del siglo I, en vez de Christus (Rodríguez Colmenero 2006: 60 y n. 45). El acto bautismal, como rito de inmersión estaría definido con la forma verbal immersit. Sobre estas premisas adapta el resto de los caracteres identificados en los dos fragmentos, resultando la siguiente interpretación:

\section{Fragmento A}

[huius pecatoris corpus im] mersit cui flebili sa[lutem datam est]

$$
\begin{aligned}
& \text { [--]tristem in[vocare--] } \\
& \text { [--m]emore libro[rum--] }
\end{aligned}
$$

\section{Fragmento B \\ [--]Chpes[tus--] \\ [--culpa]s solv[ere--] \\ [--D]omi[nus--]}

\section{ANÁLISIS EPIGRÁFICO}

Como base del análisis de una inscripción resulta obvio tener en cuenta los trazos conservados; es decir, para afrontar un estudio epigráfico con un mínimo de garantías es conveniente plantearse la siguiente cuestión: ¿de qué certezas partimos para interpretar un mensaje que nos llega incompleto?

\subsection{Certezas e incertidumbres}

Por un lado, a pesar de que los dos fragmentos conservados presentan diferencias de grosor, su pertenencia a una misma inscripción parece fuera de toda duda tras el testimonio aportado por N. Ares informando que la placa marmórea tenía forma de cuña. Además, los argumentos de carácter paleográfico esgrimidos para desvincular ambos fragmentos, tanto por el desigual tamaño de las letras como por las variantes de la letra $M$, tampoco son suficientemente convincentes porque cualquiera de las dos diferencias se constata en un único fragmento ${ }^{11}$.

Por otro lado, teniendo en cuenta los precedentes investigadores anteriormente comentados, resulta necesario constatar que los rasgos incompletos presentes en la inscripción permitan evidenciar la presencia o la ausencia de determinadas letras.

Recientemente he podido verificar la utilidad del calco publicado por N. Ares para llegar a discernir las letras incompletas de los bordes tras cotejarlo con los fragmentos depositados en el Museo Provincial de Lugo. El estado de conservación de la inscripción en ambos fragmentos es muy bueno, siendo sus trazos, incisos a bisel, profundos y anchos sin que se manifestar desgaste superficial que llegue a degradarlos, por lo que no procede la identificación de letras incompletas cuando éstas no se ajusten a los rasgos conservados.

Una vez consolidada la transcripción idónea se estará en condiciones de aceptar o rechazar alternativas interpretativas, procurando, además, evitar las que evidencien una lectura demasiado forzada. Sería conveniente desconfiar de aquellas interpretaciones que se muestran pulcras desde un punto de vista técnico pero en las que la extensión de la laguna recuperada supera ampliamente al texto conservado que la vincula, especialmente si lo restituido no se corresponde con un tópico epigráfico.

\subsection{Estudio de los caracteres incompletos no definidos}

La restitución de los caracteres ha de tener en cuenta alguna de las características formales observables en los carmina latina epigraphica de Hispania (Hoyo 2002: 147-152): frente a las dificultades inherentes de la scriptio continua se cuenta con el apoyo de la scriptio plena.

Intentaré identificar lo "inidentificable» pero omito del análisis los restos de la primera línea conservada de ambos fragmentos por carecer de información suficientemente significativa.

\subsubsection{Análisis del fragmento $A$}

Línea 2: + chpest. El trazo inclinado que precede a la C puede atribuirse tanto a una A como a una R. Lamentable-

${ }^{11}$ Las variantes de la letra M (en min... del fragmento mayor y ...om. del menor), aducidas en IRPLu 88, también se constatan dentro del fragmento mayor entre la M de min... y la de more. De todas formas, en el dibujo publicado por N. Ares estas diferencias se difuminan casi por completo. 
mente no tenemos constancia de cómo es la grafía de la letra $A$ en esta inscripción pero sí de la $R$ y, como bien señaló N. Ares (1963: 180-181), la afinidad con ésta es más que notable. Y ya no sólo por la característica terminación en la base; el ángulo de inclinación del trazo coincide plenamente con la $\mathrm{R}$ de triste y se aproxima bastante al de la otra $\mathrm{R}$ que lo tiene completo. Si se tratara de una $\mathrm{A}$-menos probable pero no descartable- el ángulo de inclinación del trazo debería ser menos agudo. Aunque incipiente, el trazo del final de la línea sólo podría atribuirse a las letras $A, M \circ N$, coincidiendo plenamente con el trazo más desarrollado del final de la línea 2 del otro fragmento, igualmente precedido por una letra $\mathrm{S}$ resaltando su similitud. La única muestra de la letra $\mathrm{N}$ está en el otro fragmento y presenta la misma inclinación.

Línea $3:+$ ssolt. El exiguo rasgo que precede a la $\mathrm{S}$ incompleta puede pertenecer a una I, a una $\mathrm{E}$ o a una V. Lo más probable es que se corresponda con el remate superior característico de la letra I. Por el contrario, todos los casos de la letra $\mathrm{E}$ presentan esa terminación con un corte vertical y para la letra $\mathrm{V}$ el ángulo del rasgo conservado es excesivo aunque según se prolongue el trazo podria corregirse. El trazo inclinado del final de la línea es muy probable que pertenezca a una letra $V$. Tendría que haber rasgos de la zona inferior para pensar además en una $X$ o en una $Y$, y si el trazo inferior se correspondiera con la zona de rotura habria restos del biselado o del color rojo (esta peculiaridad se observa al final de la tercera línea del otro fragmento). Otra posibilidad es que estemos ante una $Y$ con un trazo vertical en su mitad inferior pero hay que tener en cuenta que el ángulo del trazo es igual al de la $\mathrm{V}$ del otro fragmento.

Línea 4: ọm+. Al contrario de las pocas dudas que plantea la identificación de la 0 inicial, son muchas las alternativas que implica tener un rasgo vertical como inicio de letra al final del resto de esta línea: $B, D, E, F, H, I, K, L, N, P, R$. La letra $\mathrm{N}$ es la menos probable de estas alternativas. La única que presenta la inscripción tiene el trazo inclinado pero la combinación de enes con el trazo recto e inclinado se pude observar en otras inscripciones. La letra $\mathrm{M}$ se descarta porque las tres letras conservadas tienen el trazo inclinado.

Línea 5: +. Las alternativas de letra ante este único rasgo son B, P, R. Por matizar algo, el amplio espacio de separación con la siguiente letra podría indicar que la letra $P$ sea la menos probable de las tres.

\subsubsection{Análisis del fragmento $B$}

Línea 2: ersitcuiflebilis+. Así como al inicio de la línea conservada es clara la presencia de la letra $E_{\text {, el trazo final }}$ de la línea puede pertenecer a las letras $A, M \circ N$ por los mis- mos motivos a los comentados en el final de la segunda línea del fragmento $A$.

Línea 3: ttristemin+. Tampoco plantea dudas la letra inicial, en este caso una T. Aunque no se observa ni en el dibujo ni en la fotografía, la zona de ruptura derecha de esta línea conserva restos del bisel y de pintura roja de un trazo vertical que abarca aproximadamente la mitad superior de la altura de línea. Al igual que en la línea 4 del fragmento $A$ son varias las alternativas aplicables a este rasgo, pero que también nos indica que son muchas las letras a no tener en cuenta.

Línea 4: +ẹmore $++++0+$. El trazo vertical inicial puede pertenecer por un igual a una I o una $\mathrm{L}$, también a la letra $\mathrm{H}$ pero con menor posibilidad por la secuencia emore posterior. A continuación, cada uno de los dos rasgos siguientes puede pertenecer tanto a una I como a una L. El siguiente par de letras pueden corresponder tanto a una $B$, una $P$ o una $R$ pero el poco espacio que hay entre cualquiera de éstas y la siguiente letra da preferencia a la $P$, aunque la segunda también podría ser una $\mathrm{R}$ porque la letra 0 que le sigue permitiría esta ajustada proximidad. Por último, parece que finaliza esta línea un trazo vertical aislado que también correspondería a una $\mathrm{H}$, una I una $\mathrm{K}$ o una L.

\section{COMENTARIO CRÍTICO}

\subsection{La cuestión del antropónimo griego}

Lo que más llama la atención del fragmento $A$ es el nexo HP. Como ya hemos visto, al no existir esta secuencia de letras en latín, su presencia ha sido justificada por varias causas:

- Como un error del lapicida al escribir el nexo HR.

- Como forma cómoda del nexo PH (al no existir HP no crearía dudas al lector).

- Como el propio nexo HP al transcribir en latín terminología griega donde sí existe este nexo.

Al igual que J. del Hoyo (2002: 143-144), también soy de la opinión de que se recurre demasiado al error del esforzado lapicida para justificar el desatino a la hora de afrontar un nuevo escollo epigráfico. El error del lapicida suele ser identificable por lo obvio que es; lamentablemente el exiguo texto no permite dilucidar esa posible obviedad.

No creo que haya que objetar nada a la aparición de la secuencia hp en un epígrafe latino resultado de la transliteración del alfabeto griego. Ya hemos visto que esta circunstancia fue interpretada inicialmente por S. Mariner, donde en vez de una $R$ se incluye la letra $P$ griega (rho), y recientemente pormenorizada por A. Rodríguez para argumentar la presencia del nombre Chrestus (Rodríguez Colmenero 2006: 60) ${ }^{12}$.

12 Pero lo que riza el rizo (permítaseme la expresión) son las razones que el autor aduce para justificar la presencia de la P griega: "Agora ben, ao epigrafista traizóao o ambiente cristián en que se move e, mentres interpreta o " $X$ " do nome grego de Cristo por "Ch", no canto de compoñer o nexo "Ch ^r" co "r" latino, faino co "P[ro]" grego, "CHP", como se do cristograma dun crismón se tratasen. 


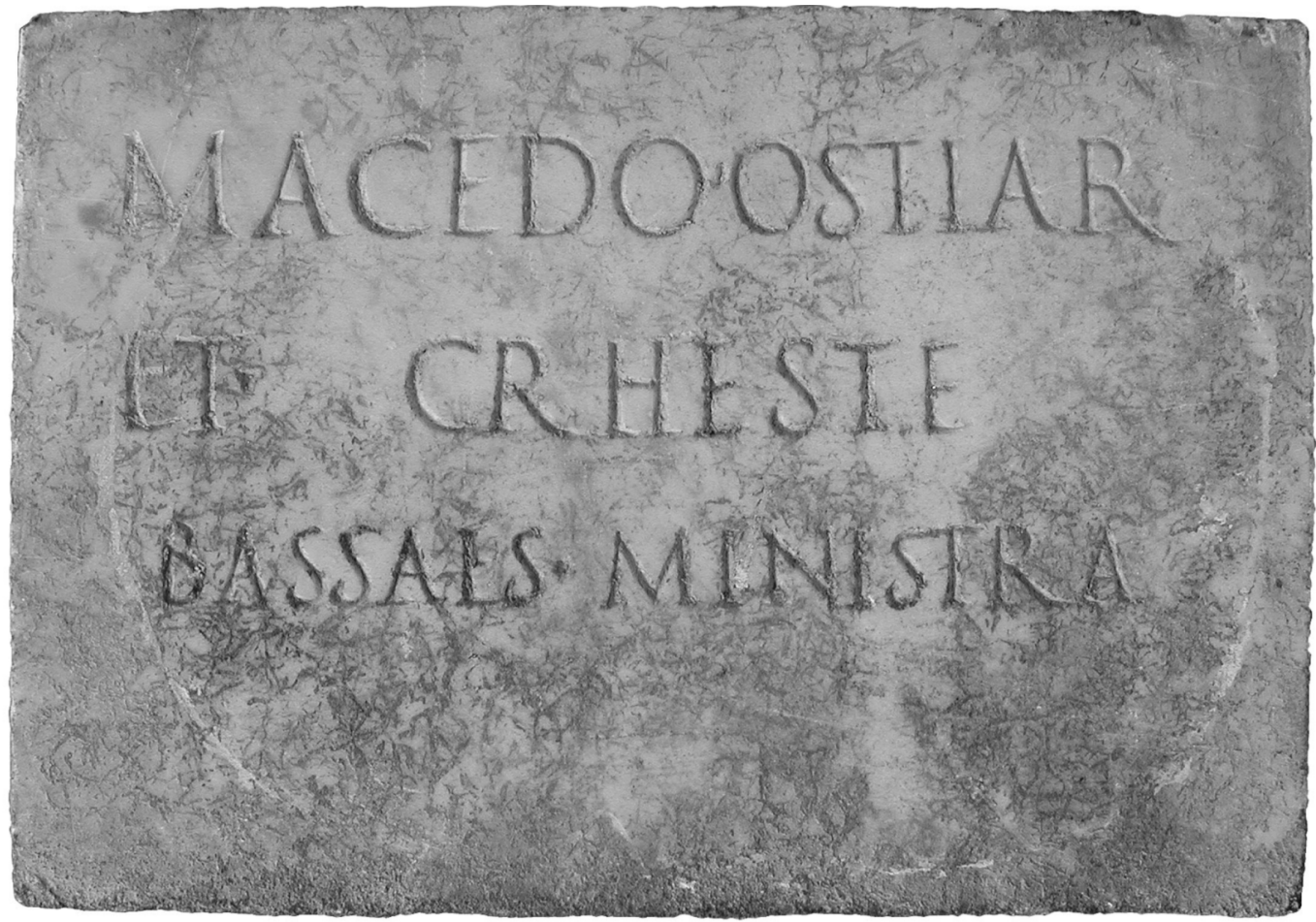

FiguRA 3. Inscripción funeraria latina con un error frecuente en la transliteración de un antropónimo griego. N. ${ }^{\circ}$ Cat. 23690, Museu Prehistòria de València (Mazzoleni et al. 2006: 419, fig. 2).

Desconozco el número de casos en los que la secuencia PH esté invertida para facilitar su nexo. No creo que este sea el caso a tener en cuenta, por lo menos en los términos aportados por J. del Hoyo (2005: 882) que lo sitúa como inicio de muchas de las palabras heredada del griego. Él interpreta ac el final de la palabra que antecedería al nexo pero no se debe separar la secuencia chp porque, como comenté antes, lo más probable es que esté precedida por la letra $\mathrm{R}$ y no por la letra $A$.

Los vestigios epigráficos señalan que la transliteración al latín de terminología griega ha provocado problemas de ubicación de la $\mathrm{H}$ muda, sobre todo fuera del ámbito de las élites culturales. Lo habitual es que tienda a desaparecer como asi lo revelan muchos ejemplos. En un caso que nos puede incumbir, como es el de los antropónimos que comienzan por "Chr", un porcentaje muy significativo, aunque no predominante, está escrito sin $\mathrm{H}$ : Cresius, Crestinus, Cresimus, Crestus, Creste... En parte esta omisión puede ser debida al carácter sintético per se del ámbito epigráfico y que, por lo tanto, al incluir expresamente la $\mathrm{H}$ exista la voluntad de acentuar el origen griego de la persona. Esta circunstancia puede tener un fiel reflejo cuando aparece escrita en un lu- gar incorrecto (fig. 3) ${ }^{13}$. Estos testimonios no son casos excepcionales ${ }^{14}$ y sirva un ejemplo que atañe a este artículo cuando en una lápida de Brindisi se escribe Trehptus en lugar de Threptus provocando la aparición de la secuencia HP; obvio error del lapicida o del autor de la dedicatoria ${ }^{15}$.

Pero este error no se puede extrapolar a nuestra inscripción, en primer lugar porque la secuencia chp sería la adecuada (presuponiendo la transliteración del griego errónea al incluir la letra rho sin transformar) y en segundo lugar porque esta rho aparece formando un nexo griego habitual ${ }^{16}$. Se podría concluir que la desubicación de la letra $\mathrm{H}$ se correspondería con un error de transliteración caracteristico de una persona cuya lengua de referencia fuese la latina frente al error de la no transformación de la letra rho, característico de una referencia lingüistica griega.

\subsection{Objeciones a transcripciones de letras incompletas}

La interpretación de la inscripción de A. Rodríguez está enteramente mediatizada por una supuesta referencia a Cris-

${ }^{13}$ Al ver esta pequeña lápida en el Museu de Prehistòria de València (Mazzoleni et al. 2006: 417-420; HEp 15, 428; AE 2006, 234) no pude más que sonreír al imaginarme, en la Roma del siglo I, a la dueña de los esclavos fallecidos dirigiéndose al lapicida en estos términos: «...y recuerde, escriba CR con H..... En otro caso localizado en Capri en la segunda mitad del siglo I, la errata Crhesime de una inscripción pudo subsanarse parciamente al corregirse cinco líneas más abajo en la forma Chresimes. (Kesel, 1988: 197; AE 1988, 343).

14 Se puede comprobar al buscar en cualquier base de datos de epigrafía latina la secuencia "crh" o "trh", por ejemplo.

15 D(is) M(anibus) / L(ucius) Valeriu [s] / T[re]hptus [- / ...] (AE 1978, 227).

16 N. Ares (1984: 120) aporta un ejemplo de nexo HP griego (Belda 1946: 165, fig.3; HAntEp 1174). 
to ${ }^{17}$ pero ya hemos visto que después de chpes no puede ir una $\mathrm{T}$. Las alternativas son la $\mathrm{A}$, la $\mathrm{M}$ o la $\mathrm{N}$, difícilmente se podria llegar a admitir una I o cualquier otra letra que empiece por un trazo íntegramente vertical -en el caso de que el incipiente rasgo inclinado corrigiese su trazado-, pero la proximidad con la $\mathrm{S}$ no permite que continúe una $\mathrm{T}^{18}$. Por las mismas razones anteriormente señaladas, tampoco son posibles las alternativas [culpa]s, in[vocare] y [m]emore.

La suma de estas evidencias me confirma la sospecha de que nos encontramos ante una interpretación bastante creativa de la inscripción al ofrecer una clara descompensación entre la extensión de las lagunas que intenta restituir y el texto conservado. Aparte de vislumbrar el resolutivo oficio del autor a la hora de solventar, con mayor o menor fortuna, lagunas epigráficas, la única novedad digna de tener en cuenta estriba en que contempla, sólo como posibilidad, los términos tristem en vez de triste y flebili en vez de flebilis donde, además, paleográficamente admite su continuación con s[alute].

Desde el punto de vista métrico se han contemplado dos de las alternativas posibles pero sin separar la secuencia flebilis. Por un lado N. Ares (1963: 181) opta por la M de morbus que le aplica un ritmo descendente. Por otro lado, J. del Hoyo (2005: 880) opta mejor por una A porque la letra M "alargaría la última sílaba de flebilis, y tendríamos un crético en vez de un dáctilon. Por mi parte, sólo procede volver a hacer hincapié en que paleográficamente también es admisible la letra N.

Para finalizar la revisión de las letras incompletas que no presentan una correspondencia unívoca, la última línea del fragmento $B$ presenta la mayor complejidad al conservar sólo la parte superior de la línea. A pesar de que se identifican claramente varias letras, la presencia de alternativas sucesivas implica un aumento de las combinaciones posibles.

La confusión está tras la secuencia emore. N. Ares opta por el término lipporum pero mejor que hacer referencia a ojos legañosos creo que en este caso es más aconsejable referirse a los ojos hinchados y llorosos porque se adapta mejor a un ambiente funerario. A. Rodríguez recurre al término librorum dentro de un carácter eminentemente cristiano más que dudable. De aceptar la posible secuencia libr optaría mejor por cualquiera de las acepciones del verbo libro.
Más Ilamativas son las conclusiones que resuelven el inicio de esta línea como memorem. J. del Hoyo opta por primar una alternativa basada en la adaptabilidad de un término frente a las evidencias paleográficas reconocidas por él mismo ( $v d$. supra). Puedo entender que aisladamente los rasgos conservados induzcan a identificarlos como tal en epígrafes con otros tipos de letra pero ni la $\mathrm{M}$ inicial ni la final deberían contemplarse en esta inscripción. Igual de incomprensible resulta la identificación de otra letra $M$ en la primera línea de este fragmento y la posterior secuencia de conjeturas que le llevan a restituir el término mobil.

\subsection{La cuestión del vínculo con los loci similes virgilianos}

Para llegar a catalogar el epígrafe de Santa Eulalia de Bóveda como un locus similis virgiliano hay que intentar definir previamente las lagunas concernientes a los versos potencialmente influidos por la obra de Virgilio. Y esto es así porque, contrariamente a lo hasta ahora indicado, el estado fragmentario de la inscripción y su estudio paleográfico no nos posibilita ser concluyentes al respecto.

Es innegable la influencia de la literatura de los autores clásicos en la poesía epigráfica latina. Esta circunstancia ya había sido evidenciada en la magna antología poética del Corpus inscriptionum Latinarum realizada por F. Buecheler (1895-1897) y finalizada en 1926 por E. Lommatzsch ${ }^{19}$. Si bien la influencia entre la poesía epigráfica, predominantemente anónima, y la de los poetas cultos ha sido reciproca (Horsfall 1986; Gómez Pallarès 1992 y 1993) resulta paradigmático el éxito de Virgilio como fuente de inspiración lapidaria ${ }^{20}$.

Uno de los pasajes de mayor influjo en los tópicos del lamento en la muerte prematura se encuentra en la Eneida (Aen. VI, 426-430) donde se describen las primeras impresiones del paso de Eneas por el preinfierno:

\begin{abstract}
Continuo auditae uoces uagitus et ingens infantumque animae flentes, in limine primo quos dulcis uitae exsortis et ab ubere raptos abstulit atra dies et funere mersit acerbo; hos iuxta falso damnati crimine mortis. ${ }^{21}$
\end{abstract} 17 A pesar de que la onomástica presente en la epigrafía latina que comienza con Chr se corresponde mayoritariamente con Chrestus y Chreste.
18 La proximidad de ambos caracteres es demasiada incluso para la existencia del nexo ST. Nexo que, significativamente, no se utiliza en la pa-
labra triste.
${ }_{19}$ Para la consulta a otros autores que han profundizado sobre el tema y que han colaborado en cimentar este aspecto de los CLE (Cugusi
1982: 66-68). La excelencia de la aportación de la obra de P. Cugusi al respecto, sobre todo tras la publicación de 1996, es a día de hoy in-
cuestionable.
20 Esta especial relevancia que obtuvo la obra del poeta Virgilio en los CLE puede ser explicado por haber sido el modelo literario del sistema
educativo de la época. Además, parte importante de la identificación de loci similes virgilianos se ha logrado gracias a la exhaustiva investi-
gación, y de innovadora metodología en su momento, aplicada en la obra de R. P. Hoogma antes mencionada (Mariner 1969: 126-129).
«Pronto se oyeron voces y un enorme vagido / y almas que lloran de niños, al principio del todo, / a los que excluidos de la dulce vida y arre-
batados del pecho, / se los llevó negro dia y en acerbo funeral los hundió; / junto a estos, los condenados por un falso crimen a muerte» (Al-
var 2002-04: 1828). 
Concretamente, el verso 429 dio mucho juego, por ejemplo, en la composición de epitafios infantiles (Boyancé 1952: 277) ${ }^{22}$. Tal es asi que P. Cugusi lo cataloga, en sus múltiples vertientes, como el pasaje virgiliano favorito, "in assoluto», de los autores anónimos de los CLE (Cugusi 1985: 178).

La vinculación del epígrafe de Santa Eulalia de Bóveda con este afortunado verso proviene de la restitución de la laguna en el comienzo de la segunda línea del fragmento $B$, en la que "debe restituirse la forma verbal mersit, que, en la epigrafía, aparece casi siempre en imitaciones del verso virgiliano en cuestión» (Hernández Pérez 2001: 19).

P. Cugusi es el primero que relaciona el verso lucense con el de la Eneida ( $v d$. supra) ${ }^{23}$. Pero esta argumentación no puede estar sólo supeditada a la forma verbal mersit; una relación estadística no puede devenir en relación literaria. Para hacer más verosímil este vínculo convendría que en la inscripción de Bóveda, además, constara algún nexo claro con la muerte prematura, concretamente, en este caso, con alguna de las referencias al funus acerbum; donde lo agrio del adjetivo acerbus, referido a la fruta inmadura, se corresponde metafóricamente con un fallecimiento precoz (Hernández Pérez 2001: 18 n. $59)^{24}$. Supongo de igual opinión a P. Cugusi cuando con [acerbo funere $m$ ]ersit cvi flebilis plantea una restitución eficiente al tener en cuenta estos mismos parámetros, en la que además utiliza la misma forma nominal y adjetival que Virgilio, denotando cierto grado de artificialidad. A favor de esta propuesta se encontraría el hecho de aplicar una solución epigráfica semejante a otras inspiraciones virgilianas.

Pero otros poetas latinos de renombre también han utilizado este adjetivo en los mismos términos, donde es acompañado por el sustantivo funus o por alguno de sus sinónimos. Este y otros aspectos del empleo literario de acerbus son tratados en un interesante artículo de C. Fernández en el que, en unas de sus conclusiones, califica de esporádico y marginal el uso que hace Virgilio del adjetivo acerbus asignado a contextos de muerte prematura. Teniendo además en cuenta que algunos de los paralelos localizados en los CLE son anteriores a Virgilio y que en este autor se manifiestan muchas expresiones de la literatura epigráfica (Gómez Pallarès 1992: 199 y 1993b: 276-277), no es posible catalogarlo como el máximo responsable de la expansión y especialización del adjetivo acerbus (Fernández Martínez 2003: 330).

Todo indica, como bien nos recuerda la autora del artículo, que este tipo de expresiones forman parte de la cultura epigráfica, tan representativa de la civilización romana, en la que es notoria una literatura callejera (Sanders 1977: 45-55) ${ }^{25}$ en la que, en un fenomenal escaparate, se manifiesta un intercambio de ideas entre los escritores consagrados y los anónimos autores epigráficos ${ }^{26}$.

Por lo tanto, la mera presencia de la forma verbal mersit, y menos aún su rastro, no es garantía suficiente para la identificación en un CLE de un locus similis virgiliano. Por el contrario, sus posibilidades de acierto aumentarían considerablemente en el caso de encontrarse acompañada de algún rastro del adjetivo acerbus ${ }^{27}$.

Más que la clara connotación virgiliana para referirse a un fallecimiento prematuro por medio de [acerbo funere mersit], en la lápida lucense bien podría relacionarse esta circunstancia mediante una expresión más simple y escueta como es [pu]er sit, como ya vimos en IRPLu 88. El problema de este caso es que las opciones se abren a más alternativas como son mulier, frater, mater y pater, por ejemplo. Debido a lo especial de la relación paternofilial, en las dos últimas opciones también podría entreverse un caso de mors immatura ante la posibilidad de referirse con cui flebilis tanto al niño fallecido como a cualquiera de sus desesperados padres (Velázquez 1996: 102-103). Un buen ejemplo de ello y de las posibles similitudes con la inscripción lucense se puede ver en el siguiente carmen epigráfico que le dedica una madre a su hija fallecida a los dos años ${ }^{28}$ :

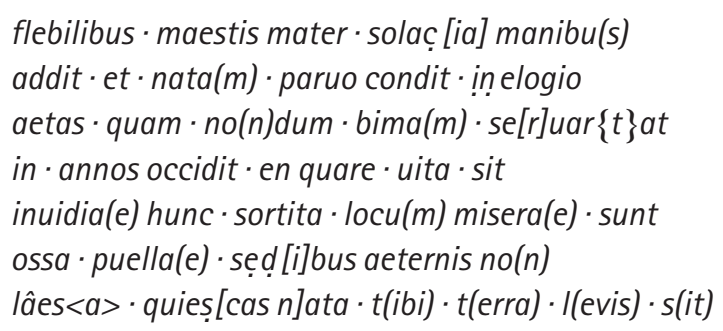

22 R. P. Hoogma (1959: 285-287) ofrece una relación de CLE inspirados en este verso. R. Hernández incluye referencias bibliográficas con distintas modalidades de imitación en una interesante aportación dentro del ámbito de la Península lbérica (Hernández Pérez 2001: 16-20) en donde sorprende tanto las pocas referencias en relación con el resto del Imperio como su temprana cronología (sobre este último aspecto, además, Gómez Pallarès 1995b: 154-155).

${ }^{23}$ Tanto S. Mariner (1960: 326) como N. Ares restituyen igualmente mersit pero ninguno de los dos lo identifica como entronque virgiliano, lo que llama la atención por lo significativo que puede llegar a ser en el caso del primero. N. Ares (1963: 181), además, quiere ver el rasgo del principio de la letra $M$ en el final de la segunda línea del fragmento A, pero la forma de la rotura de éste lo imposibilita porque el espacio generado en la unión de los dos fragmentos por este punto implica necesariamente la presencia de dos letras como mínimo.

24 Para las distintas acepciones de acerbus (Fernández Martínez 2003: 318-320).

25 Posteriormente, G. D. Susini (1982: 13) coadyuvará en la importancia de insistir en esta afortunada reflexión.

${ }^{26}$ El planteamiento esencial de este influencia mutua se atribuye a R. Chevallier (1972: 52-58).

27 A pesar de que el 69\% de los CLE con la palabra mersit está acompañada del adjetivo acerbus. Esta proporción se puede comprobar tanto en el "vademécum» de P. Colafrancesco y M. Massaro (1986: 463) con una relación 13/9 como en la consulta a la base de datos online Epigraphic-Datenbank Clauss-Slaby <http://www.manfredclauss.de> (07/10/2010) que ofrece una relación de 26/18 tras las consultas («mersit») y ("mersit» and "acerb»). En la consulta a la base de datos no se contabilizó el CLE de Santa Eulalia de Bóveda con el que totalizarian 27.

${ }^{28}$ Lápida datada entre finales del siglo I y principios del II (Reciente colaboración en Fernández Martínez 2007: 205-211, además Velázquez 1996: 110 n. 101; Hernández Pérez y Gómez Font 2000; Hernández Pérez 2001: 124-125 (132); HEp 7, 1109; HEp 10, 669; AE 2000, 741). 
Con el único rastro ersit nunca debería definirse como locus similis virgiliano a una inscripción poética, pero, contrariamente, puede aumentar considerablemente esta posibilidad si otros de sus versos así lo aconsejan. Este es el caso de la secuencia tristemin localizada en el siguiente verso (tercera línea del fragmento B), que ha sido restituido como triste ministerium para aludir a la expresión utilizada por Virgilio para referirse a la afligida encomienda de la incineración del trompetista Miseno, compañero de fatigas de Eneas (vd. supra).

Pero si observamos detenidamente el fragmento en cuestión se puede comprobar que existe una clara diferencia entre el mayor espaciado de las letras de la tercera línea frente a la de la segunda, en la que el término flebilis aparece tan apretado que incluso modifica el ángulo recto de las letras L. Esto me hace sospechar que la restitución de $\min$ por ministerium no sea la más adecuada métricamente y haya que pensar en un término con menos letras y con el que, con toda probabilidad, se finalice el verso ${ }^{29}$.

La opción del verbo minor me parece más ajustada (nunca mejor dicho), tal es el caso de la forma pasiva aportada por F. Arias et al. (vd. supra). La expresión triste minetur también se observa como final de hexámetro dactílico de Juvenal: "haec tamen ignorat quid sidus triste minetun (Sat. VI, 569), en el que alude al desconocimiento de los augurios funestos. También Claudio Claudiano en su épica de ultratumba sobre el rapto de Proserpina nos habla de amenazantes presagios ofrecidos en sueños: "saepe monent nullusque dies non triste minatur / augurium. .... (rapt. Pros. III, 125).

Este factible final de verso puede sugerir que la inscripción de Bóveda fuera elaborada, al menos parciamente, mediante la técnica del centón (Barrio 1991: 61-62; Velázquez 1996: 91-92). Aspecto este que, curiosamente, resultaría un poco más evidente si recuperamos a Virgilio como fuente de inspiración, igualmente dentro de la temática de presagios funestos, cuando finaliza uno de sus versos con una alusión a Minerva: «...scit triste Mineruae» (Aen. XI, 259). La amena$z a$, personificada esta vez en la adaptación romana de Palas Atenea, estriba en que bajo el paso de su constelación se desencadenó una tempestad sobre las embarcaciones griegas que volvían de la guerra de Troya por la ofensa que Áyax había hecho a la poderosa diosa.

La restitución [sci]t triste Min[ervae] resulta menos versátil que otras opciones como es la que utiliza el equivalente minetur, más maleable en una inscripción lapidaria y más oportuna para una época, patentizada a partir de finales del siglo I, cuando un nuevo paganismo deja a un lado el lastre mitológico y pasa a ser interiorizado por el hombre y que, en palabras de P. Veyne (1987: 212-227), deviene en desasosiego como resultado de un anhelo de seguridad profundo.
Pero no pretendo ser categórico ni en esta ni en otras cuestiones. Sólo incidir en que la vinculación de la inscripción de Santa Eulalia de Bóveda con los loci similes virgilianos, y la de algunos otros versos de los CLE, pueden estar condicionados por la dependencia de la precisa obra de R. P. Hoogma. Me hago eco de S. Mariner (1969: 129) cuando ya advertía de la preponderancia de la influencia de la obra de Virgilio en los CLE:

"I...Conste con toda sinceridad, sin embargo, que una parte de dicho predominio puede deberse a que no se cuenta para los restantes grandes nombres de la poesía latina (ni, desde luego, para los no tan grandes) con la exhaustiva investigación que para las imitaciones virgilianas supuso la obra capital del malogrado R. Hoogma...n.

Este éxito de Virgilio no sólo se observa en relación cuantitativa con el resto de inscripciones métricas, su influencia se detecta en diferentes versos de una misma composición, en lo que S. Mariner (1969: 130) califica como intensidad de la imitación virgiliana. Pero el grado de esta intensidad puede ser alterado por un proceso mimético viciado, donde la identificación de un entronque sólo es avalada por la mera presencia de otro en el mismo epigrama. Este sería el caso de la restitución [m]ersit ante la presencia de otro verso en el que, aparentemente, se restituye con mayor claridad el entronque triste min[isterium].

Resultaría conveniente, por lo tanto, que a la hora de revisar aquellos carmina latina epigraphica en los que se hayan identificado influencias literarias de un mismo autor, or-

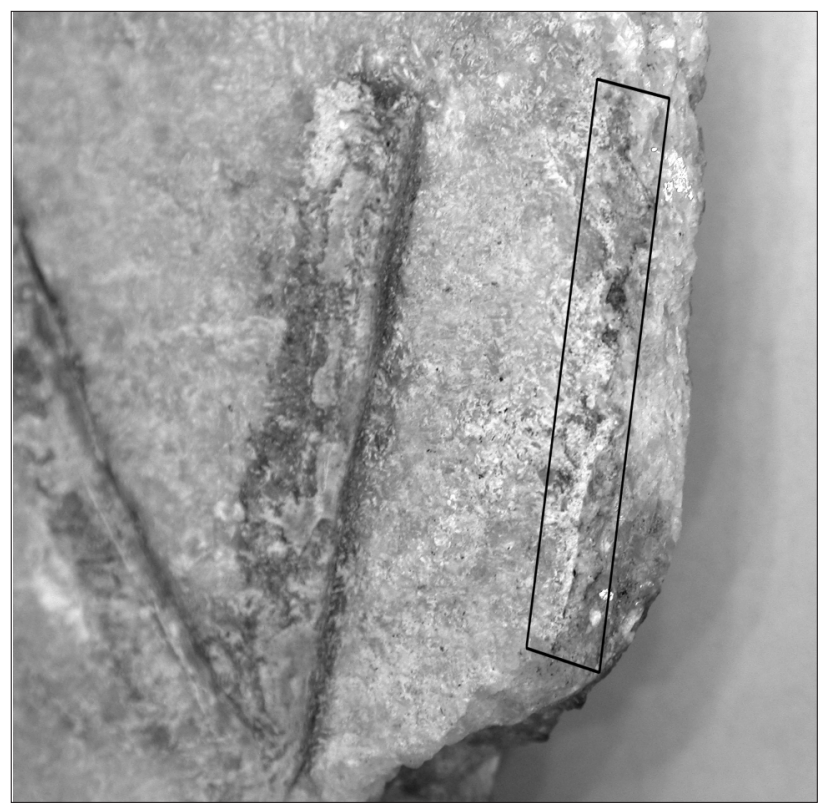

FigURA 4. La zona marcada señala el área aproximada con presencia de restos de color rojo, tanto en la superficie como en los restos del biselado conservados en la zona de rotura (foto del autor).

${ }^{29}$ Podría restituirse aquí con el término ministerium, en el caso de darse la circunstancia que los pies del verso fueran menores y se dispusieran alineados tanto a la izquierda como a la derecha, pero no me consta que ésta sea una formulación caracteristica de los CLE. 
ganizar estos entronques categorizándolos en relación a su dependencia jerárquica, para que sobre este tipo de estructura puedan asentarse las bases que posibiliten cuestionar, al menos, las evidencias de su existencia.

Finalmente, he de incluir algunas apreciaciones que refuerzan esta argumentación detectadas tras realizar comprobaciones de última hora sobre los dos fragmentos, ante la posibilidad de que algunas letras no estuvieran correctamente reflejadas en el dibujo realizado por N. Ares $^{30}$. Tal es el caso de la letra $L$, en la que debía de acusarse más su desviación del ángulo recto en el dibujo del fragmento $B$ (especialmente la primera de ellas) y, por el contrario, reducirla en la $L$ del fragmento $A$. En la letra $M$ también identifico diferencias. Únicamente una de ellas es fiel reflejo del original puesto que en solo una de las dos crestas, en estas letras situadas en la línea 4 de ambos fragmentos, acaba en punta.

Pero lo realmente trascendental surgió cuando realizaba una fotografía para mostrar el color rojo y el resto de trazo biselado localizados a continuación de la secuencia min porque estas particularidades no se distinguian en las ilustraciones. Una fotografía macro me proporcionaba una agradable sorpresa al detectar que en la zona de la fractura quedan restos bien definidos de una línea recta en rojo que transcurre paralelamente al trazo inclinado de la letra N (fig. 4). Esta evidencia me permite ratificar en un $99 \%$ la propuesta de que no se debe restituir el sintagma virgiliano triste ministerium. Mi preferencia, ya manifestada, de vincular los indicios epigráficos al verbo minor resulta ahora más evidente si se restituye en su forma minatur.

FIGURA 5. CIL II 3256 = CLE 1196, Baesucci, Vilches, Jaén.

N..$^{\circ}$ Inv. 16536, Archivo del Museo Arqueológico Nacional,

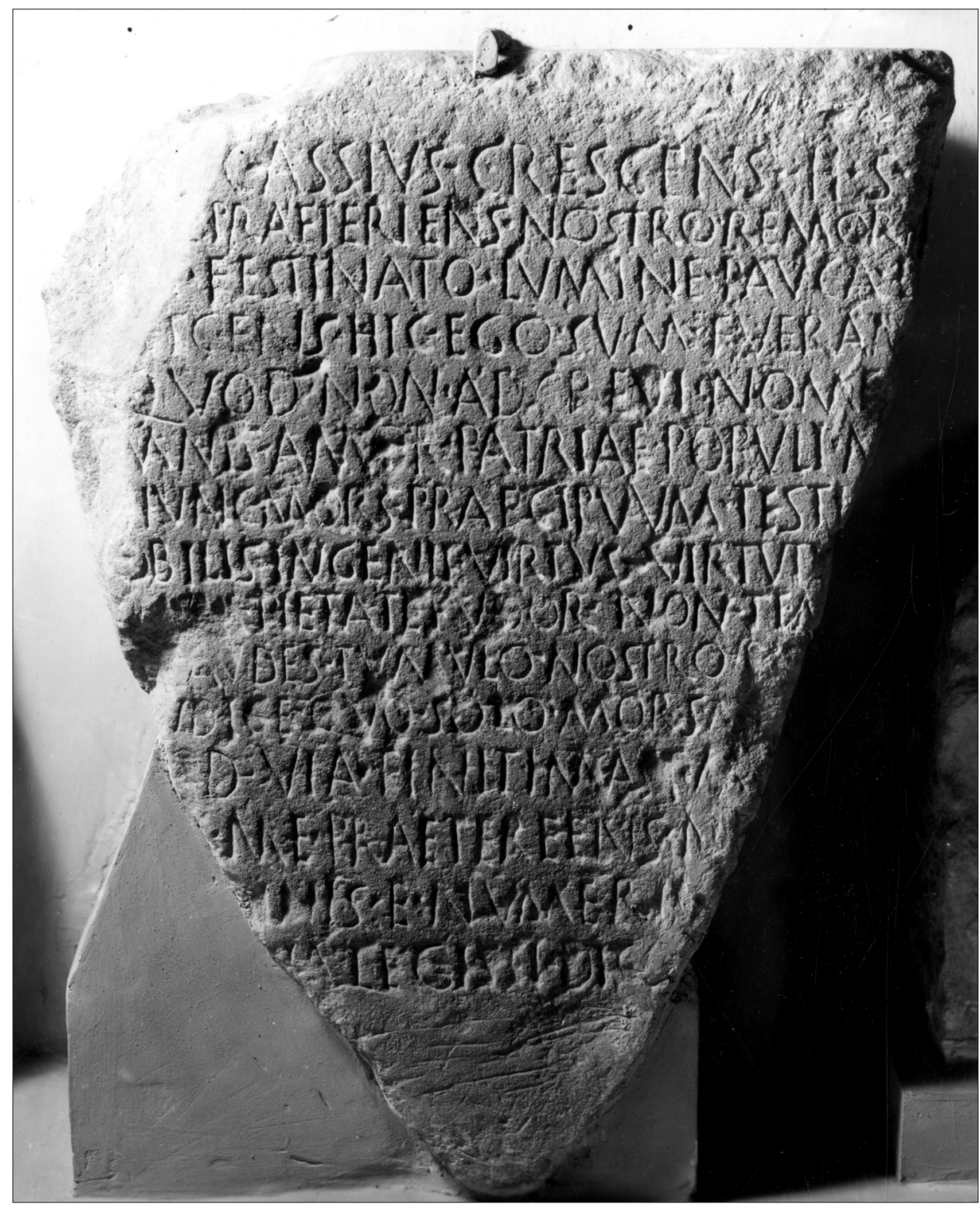

Creo que es un buen momento para agradecer al Museo Provincial de Lugo, y permitanme personalizarlo en la conservadora 0. Carnero, las facilidades de estudio de la inscripción. Aprovecho la oportunidad para solicitar públicamente que tanto estas piezas, como otras del propio monumento depositadas en este museo, sean trasladadas del área de almacén a las salas de exposición permanente. 


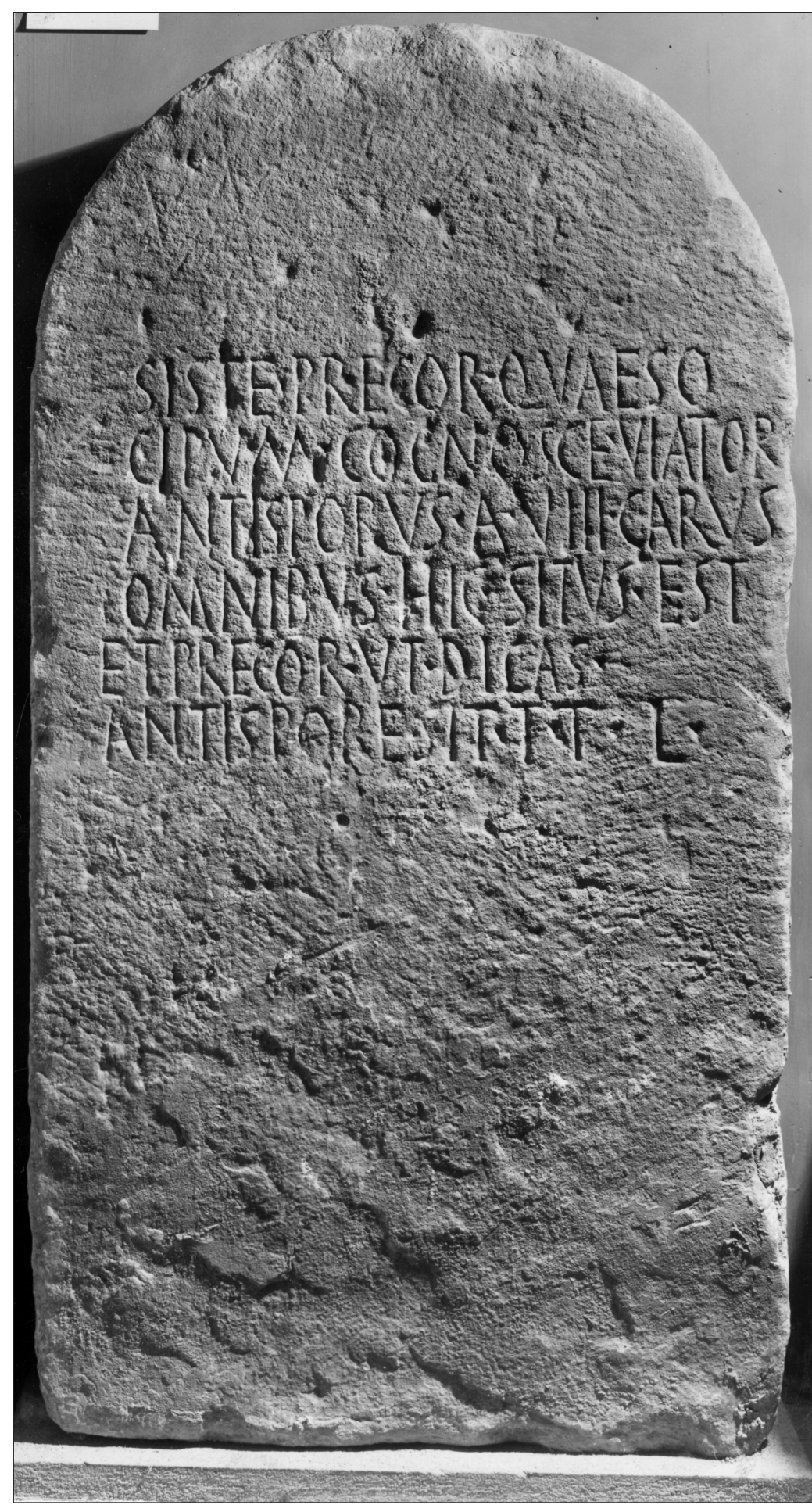

FIGURA 6. CIL II 5907 = CLE 1193, Castulo, Linares, Jaén. N. ${ }^{\circ}$ Inv. 16539, Archivo del Museo Arqueológico Nacional, Madrid.

\subsection{La cuestión de la cronología}

Este problema del apriorismo virgiliano se complica cuando la presencia de un entronque también condiciona otros aspectos de una inscripción métrica, como puede ser el de su cronología. Soy consciente del terreno resbaladizo en el que me estoy metiendo pero considero que no debo finalizar este artículo sin dejar, al menos, planteada esta cuestión.

La inscripción lucense se ha inscrito en un ámbito cronológico tardío (siglos III-IV) en gran medida por la identificación del sintagma triste ministerium (Hoogma 1959: 281) ${ }^{31}$ y por su paleografía; pero ningún autor ha llegado a explicitar estas caracteristicas paleográficas (Hernández Pérez 2001: 20; Hoyo 2005: 882) ${ }^{32}$.

Por el contrario, se pueden apreciar algunos indicios en varias letras que referencien la presencia de una paleografía más temprana (Batlle 19632: 7-17; López Barja 1993: 35-38), como por ejemplo:

- Poca diferencia en el ancho de los lóbulos en la B.

- Líneas transversales iguales en la F.

- Los tres ángulos iguales de la M.

- La inclinación de la N.

El tipo de letra, menos solemne que la capital cuadrada, se inscribe dentro de la denominada capital rústica cuya mayor libertad de trazado no impide la presencia de inscripciones elegantes y cuidadas.

Entre las inscripciones métricas hispanas identifico algunas de grafía equivalente, dos localizadas en la provincia de Jaén ${ }^{33}$ CIL II 3256 = CLE 1196 (fig. 5) y CIL II 5907 = CLE 1193 (fig. 6), datadas en el siglo I y otra recientemente descubierta en Segobriga (fig. 7) de principios del siglo II. La salvedad más significativa radica en que en ninguna de las tres consta la inclinación característica de la $\mathrm{N}$ de la inscripción lucense.

La lápida de Segobriga, en la que se identifica una onomástica local presente a lo largo del siglo I, tiene la peculiaridad, por un lado, del uso de la I longa, lo que facilita datarla en el primer tercio del siglo II por ser

31 Con más detalles cronológicos en Colafrancesco y Massaro 1986: 472.

32 A J. del Hoyo (2005: 881), además, esta cronología tardia le permite restituir [patr]es en vez del virgiliano parentes, manifestándose una peculiar identificación mimética ( $v d$. supra) de un entronque virgiliano.

33 Con múltiples referencias de ellas (Hernández Pérez 2001: 306). 


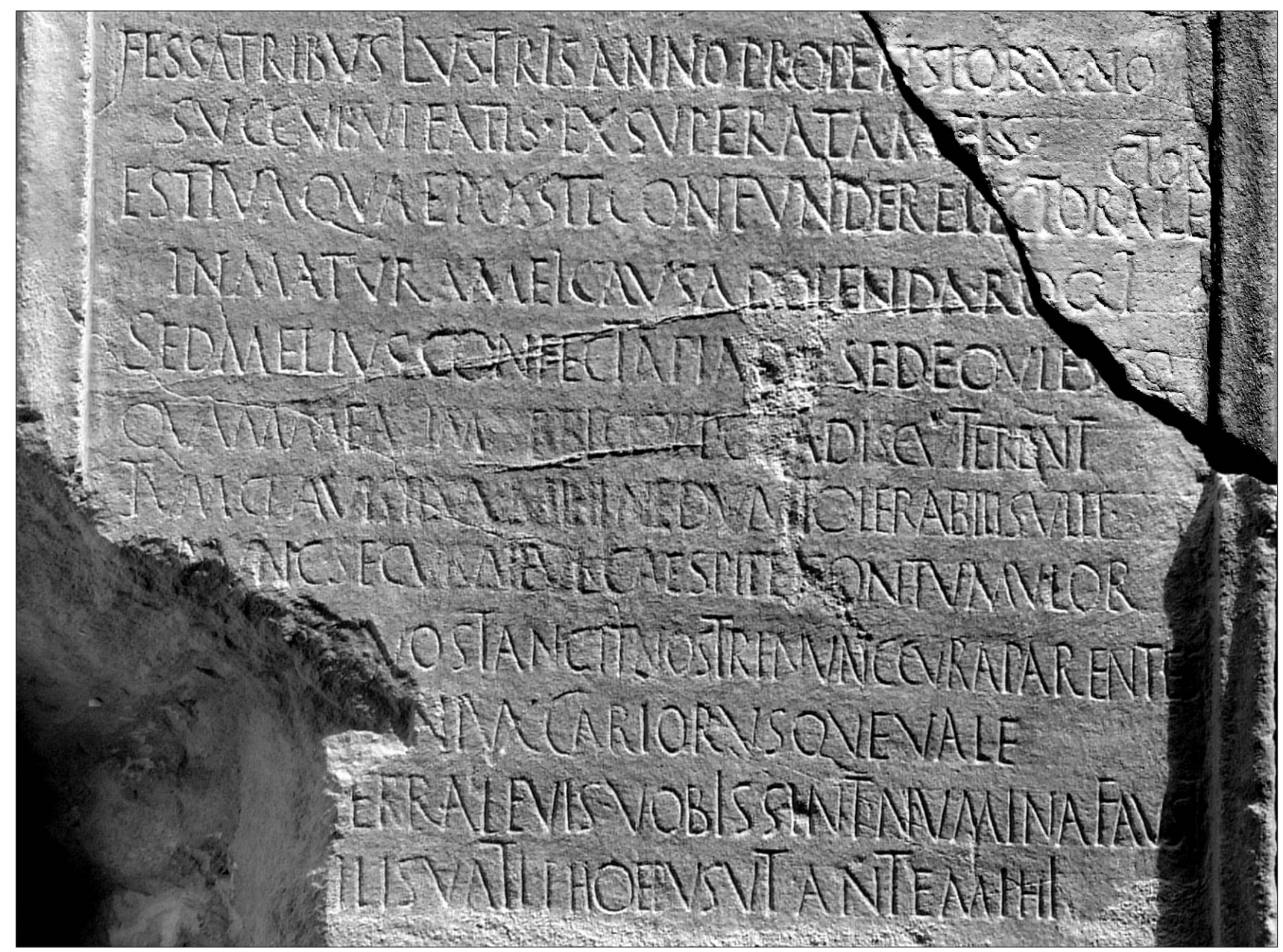

FiguRA 7. Detalle epigráfico de la lápida de Iucunda. Parque Arqueológico de Segobriga, Saelices, Cuenca (Fernández Martínez et al. 2007: 51, fig. 1).

frecuente su uso en época de Adriano (Fernández Martínez et al. 2007: 58-59), por otro lado ya presenta una marcada diferencia en el tamaño de los lóbulos de la B. Estas características diferenciadoras en su paleografía podrían estar indicando un hito cronológico.

De la misma provincia de Ciudad Real, el carmen CIL II/7 775 presenta la peculiaridad de que una de las $\mathrm{N}$ tiene una inclinación similar a la de Bóveda ${ }^{34}$; al igual que la forma, anchura y profundidad de la mayoría de sus letras que se inscriben cronológicamente en la primera mitad del siglo I por las características de la letra M (Fernández Martínez 2007: 212-215).

Teniendo en cuenta lo aquí explicitado considero que pueden verse reducidas las posibilidades de que la datación de la inscripción de Santa Eulalia de Bóveda sobrepase la primera mitad del siglo II.

\section{CONCLUSIONES}

En estos fragmentos sólo tenemos la certeza de que nos encontramos ante una lápida de mármol que cuenta con las caracteristicas formales y con terminología propia de las inscripciones en verso. Entre estos términos se encuentran flebilis y triste que nos encaminan, a su vez, hacia contenidos propios de la epigrafía sepulcral.

Pero nada nuevo aportaría si concluyo con esto, aunque es fundamental hacer hincapié en intentar definir certezas 0 , en caso contrario, precisar su grado de incertidumbre. Se ha visto con el análisis de los caracteres incompletos al comprobar que contemplando un rastro de letra en sus debidos términos no sólo se descartan compañeras de alfabeto sino que se puede contradecir las evidencias que proponían al carmen de Santa Eulalia de Bóveda como un locus similis virgiliano.

\footnotetext{
34 Publicada en Alföldy (1987: 234 lám. V) y Fernández Martínez (2007: 212). La premura en la entrega de este artículo no me ha permitido aportar una fotografía con la suficiente calidad para su publicación y estudio. Se accede a una en la siquiente dirección de Internet $<$ http://www2.uah.es/imagines_cilii/fotos_cilii/7/CILII7,0775.jpg> del Centro CIL II2 que se encuentra instalado en la Universidad de Alcalá
} de Henares <http://www2.uah.es/imagines_cilii/inicio.htm> 


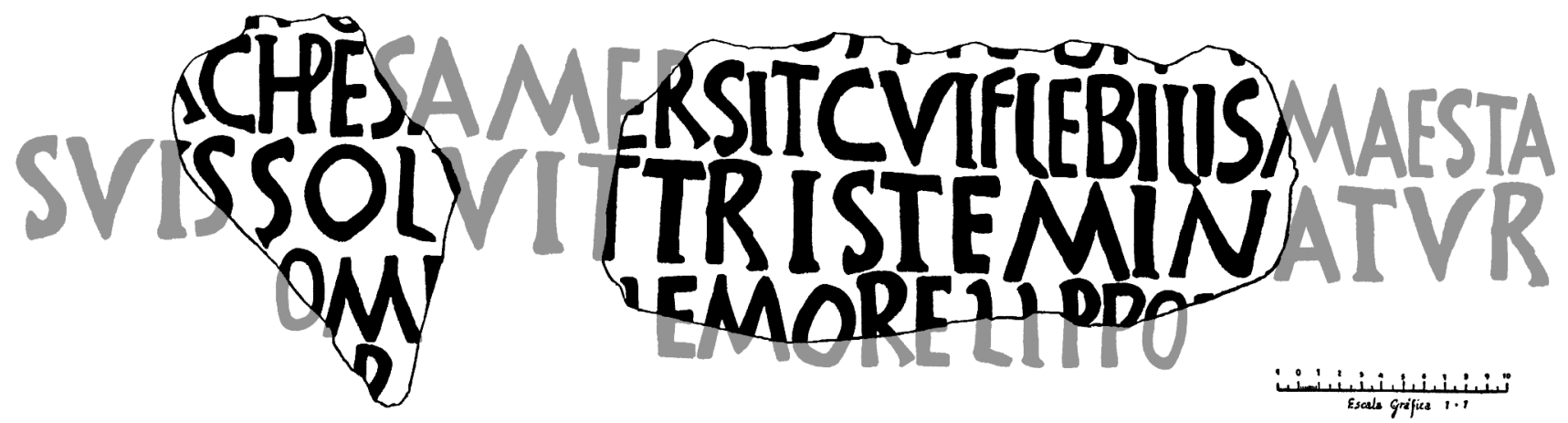

FiguRA 8. Reconstrucción hipotética y parcial de la inscripción de Santa Eulalia de Bóveda (dibujo del autor a partir de la fig. 2).

La dificultad para afrontar la recuperación del testimonio oculto entre las parcas letras de la inscripción es manifiesta. Además, ahora tampoco contamos con la referencia de la inspiración literaria del autor que nos permita tener una idea aproximada del sentido profundo de lo expresado.

\subsection{Texto}

Con lo argumentado hasta ahora, me atrevería a proponer una lectura parcial que englobe a los dos fragmentos, teniendo en cuenta que esta parcialidad atañe tanto al carácter incompleto como selectivo de la propuesta:

$$
\begin{aligned}
& \text { [--][-c.2-][--][-c.6-][--] } \\
& \text { [--]r Chpesa [m]ersit cui flebilis m[aesta] } \\
& \text { [--][su]!s solv [i]t triste minạ [tur] } \\
& \text { [--]om+[-c.2-]+e more !!̣pọ+[-c.6-] } \\
& {[--]+[--]}
\end{aligned}
$$

\subsection{Aparato crítico}

\section{A:}

I. 2: Chres[ismus?] Mariner; hiRCl-PES Ares ${ }^{35}$; $A C H^{\wedge} P E S+$ Hoyo; Chrest[us] Rodríguez Colmenero.

I. 3: dISSOLVi Ares; [PATR]ES SOLV[ERVN] Hoyo; solv[ere] Rodríguez Colmenero.

I. 4: cOMltia Ares; [D]omi[nus] Rodríguez Colmenero.

I. 5: PHoyo.

B:

I. 1: MỌB!̣! L? Hoyo.
I. 2: Morbus Ares; [acerbo funere m]ersit Cugusi; A[--] Hoyo; [huius pecatoris corpus im]mersit cui flebili sa[lutem datam est] Rodríguez Colmenero.

II. 2-3: [PV]ER SIT CVI FLEBILIS [ALIOUID/NE] TRISTE MIN[ETVR.../...] IRPLu ${ }^{36}$.

I. 3: min[isterium] Mariner, Ares, Hernández Pérez; mini[sterium] Hoyo; tristem in[vocare] Rodríguez Colmenero.

I. 4: Amore? Vázquez Saco; LE MORE LIPPOrum Ares; MEMOREM? PRO Hoyo; [m]emore libro[rum] Rodriguez Colmenero.

Dos de estas propuestas también logran una ubicación relativa de ambos fragmentos en el espacio de la lápida identificando las siguientes palabras nexo:
$A B:$
I. 2: mersit Ares.
I. 3: dissolvit Ares; solverunt Hoyo.
I. 4: comitiale Ares.

\subsection{Comentario}

En mi propuesta, el tentador suis solvit como enlace entre fragmentos condiciona Cĥpesa y mersit. Sólo he localizado una Cresa en la provincia de Dalmatia, en la actual Bosnia y Herzegovina (Iปug 3, 01612) ${ }^{37}$. Tras flebilis también podria optar por mater pero maesta es una alternativa más genérica que condiciona menos el sentido de la inscripción. No es infrecuente la combinación de minatur con otro verbo en voz activa en el mismo verso y suele implicar la prolongación de sus frases a los adyacentes. La cuarta línea está muy condicionada al aislamiento de la secuencia

\footnotetext{
35 En su propuesta refleja en minúsculas el texto restituido.

${ }^{36}$ No consideran que los dos fragmentos pertenezcan a la misma lápida.

37 Evidentemente, si se admite Cĥpesi[--] los casos y las alternativas aumentarían considerablemente.
} 
more pero no necesariamente tendría que estar reflejada esta palabra.

Lo fundamental de esta interpretación es que en ella se refleja la inquietud ante una muerte si no anunciada sí previsible. Y como parece ser que no hay cosa más predecible que la muerte, en cierta medida esta cuestión también la distanciaría de la idea de encontrarnos ante la evidencia de un ejemplo de mors immatura.
A modo de colofón incluyo un dibujo en el que se muestra cómo quedaría esta modesta interpretación en la lápida (fig. 8). Realizado sin ánimo de ser concluyente, más bien todo lo contrario, espero que a este puzle iniciado por N. Ares se continúen modificando o incorporando nuevas piezas $y$, por supuesto, un poquito de ritmo [métrico] ${ }^{38}$.

VIGO, otoño de 2010

\section{ABREVIATURAS}

$A E=$ L'année épigraphique, Paris.

$\mathrm{CIL}=$ Corpus inscriptionum Latinarum.

$\mathrm{CLE}=$ Carmina latina epigraphica . Si va seguido de un número hace referencia a un carmen epigraphicum de la antología de F. Buecheler (1895-1897) y del suplemento de E. Lommatzsch (1926).

HAntEp = Hispania Antiqva Epigraphica, Madrid.

$\mathrm{HEp}=$ Hispania Epigraphica, Madrid.

IDug = Inscriptiones Latinae quae in lugoslavia ... repertae et editae sunt Ljubljana 1963-1986.

IRG-II = VÁzouez SACO, F. y VÁzQuez SeIJAS, M. 1954: Inscripciones Romanas de Galicia. II Provincia de Lugo. Instituto de Estudios Gallegos Padre Sarmiento. Santiago de Compostela.

IRPLu = ARIAS, F. et al. 1979: Inscriptions romaines de la province de Lugo. Diffusion de Boccard. Paris.

\section{BIBLIOGRAFÍA}

ALFöLDY, G. 1987: «Epigraphica Hispanica IX. Inschriften aus Ciudad Real». Zeitschrift für Papyrologie und Epigraphik 67: 225-248.

Alvar, A. 2002-2004: «Virgilio, Eneida VI (traducción rítmica)». Archivo de Filología Aragonesa 59-60/2: 1817-1840.

ARES, N. 1962: "Santa Eulalia de Bóveda. Dos lisiados y un monasterio». Boletín de la Comisión Provincial de Monumentos Históricos y Artísticos de Lugo 57-58: 115-123.

- 1963: "Santa Eulalia de Bóveda. Mensaje de la Cigüeña». Boletín de la Comisión Provincial de Monumentos Históricos y Artísticos de Lugo 59-60: 173-182.

- 1964: "Santa Eulalia de Bóveda: Otro relieve en el pórtico». Boletín de la Comisión Provincial de Monumentos Históricos y Artísticos de Lugo 61-62: 237-246.

- 1984: "Inscripciones lucenses medievales en verso». Boletín do Museo Provincial de Lugo 2: 119-134.

BARRIO, M. F. del 1991: "Formas y fórmulas de versificación en las inscripciones sepulcrales latinası. En L. Ferreres (ed.): Actes del IX Simposi de la Secció Catalana de la SEEC. St. Feliu de Guíxols, 13-16 d'abril de 1988. Treballs en honor de Virgilio Bejarano I. Barcelona: 55-64.

BATLle, P. 1963²: Epigrafía latina. Instituto de Filología Antonio de Nebrija. Barcelona.

BeLdA, J. 1946: "Museo arqueológico provincial de Alicante». Memorias de los Museos Arqueológicos Provinciales (extractos) 6: 157-165.

BoyAnCÉ, P. 1952: "Funus acerbum». Revue des Études Anciennes 54: 275-289.

BueCheleR, F. 1895-1897: Carmina Latina Epigraphica. In aedibus B. G. Teubner. Leipzig.

Chamoso, M. 1952: "Sobre el origen del monumento soterrado de Santa Eulalia de Bóveda (Lugo)». Cuadernos de Estudios Gallegos 22: 231-251.
Chevallier, R. 1972: Épigraphie et littérature à Rome. Fratelli Lega. Faenza.

Colafrancesco, P. y MASSARO, M. 1986: Concordanze dei carmina latina epigraphica. Edipuglia. Bari.

CugusI, P. 1982: "Carmina Latina Epigraphica e tradizione letteraria». Epigraphica 44: 65-107.

- 19962: Aspetti letterari dei Carmina Latina Epigraphica. Pàtron. Bologna.

- 2007: Per un nuovo Corpus dei Carmina Latina Epigraphica. Metariali e discussioni. Atti della Accademia Nazionale dei Lincei, Memorie XXII-1. Bardi. Roma.

Fernández Martínez, C. 2002: "Las restituciones verosímiles en los CLE conservados». En J. del Hoyo y J. Gómez Pallarès (eds.): Asta ac pellege. 50 años de la publicación de "Inscripciones Hispanas en verso", de S. Mariner. Signifer Libros. Madrid: 163-182.

- 2003: "Acerbus : La amargura de morir antes de tiempo». Emerita 71/2: 313-337.

- 2007: Carmina Latina Epigraphica de la Bética Romana. Las primeras piedras de nuestra poesía, Universidad de Sevilla, Sevilla.

- et al. 2007: "Mors mala solvit : Nuevos CLE hallados en Segobriga (Hispania Citerior)». Zeitschrift für Papyrologie und Epigraphik 161: 47-60.

Gómez PAllarès, J. 1992: "Carmina Latina Epigraphica i poesía llatina: el camí invers». En Actes del Xè Simposi de la Secció Catalana de la SEEC. Tarragona, 28 a 30 de novembre de 1990. Homenatge a Josep Alsina II. Tarragona: 195-201.

- 1993: "Aspectos epigráficos de la poesía latina». Epigraphica 55: 129-158.

- 1993b: "Otros ecos en la Eneida de Virgilio: La "Evidencia» de los Carmina Latina Epigraphican. Helmántica 44: 267-280.

- 1995: "Initia de los Carmina Latina Epigraphica Hispaniae (Conventus Tarraconensis) I». Faventia 17/1: 67-87.

- 1995b: "Cultura literaria en el corpus de los CLE Hispaniae hasta época Flavia». En F. Beltrán (ed.): Roma y el nacimiento de la cultura epigráfica en Occidente. Institución Fernando el Católico. Zaragoza: 151-162.

Gómez-Moreno, M. 1949: "Santa Eulalia de Bóveda». En Misceláneas. Historia - Arte - Arqueología. Primera Serie. La Antigüedad. Instituto Diego Velázquez. Madrid: 415-423.

Hernández Pérez, R. 2001: Poesía latina sepulchral de la Hispania romana. Estudio de los tópicos y sus formulaciones. Universidad de Valencia. Valencia.

Hernández Pérez, R. y Gómez Font, X. 2000: "Un nuevo "Carmen epigraphicum» hispano: edición y comentario». Epigraphica 62: 101-110.

Hoogma, R. P. 1959: Der Einfluss Vergils auf die Carmina Latina Epigraphica. Eine Studie mit besonderer Berücksichtigung der metrischtechnischen Grundsätze der Entlehnung. North-Holland publishing company. Amsterdam.

HORSFALL, N. 1986: "Virgil and the inscriptions. A reverse view». Liverpool Classical Monthly 11/3: 44-45.

Hoyo, J. del 2002: "La ordinatio de los CLE Hispaniae». En J. del Hoyo y J. Gómez Pallarès (eds.): Asta ac pellege. 50 años de la publicación 
de "Inscripciones Hispanas en verso", de S. Mariner. Sígnifer Libros. Madrid: 143-162.

- 2005: "Carmina Latina Epigraphica del noroeste hispano» en A. Alvar (coord.): Actas del XI Congreso Español de Estudios Clásicos. Santiago de Compostela 2003 II. Sociedad Española de Estudios Clásicos. Madrid: 877-886.

KESEL, H. 1988: "Einige inschriften von der insel Capri». Zeitschrift für Papyrologie und Epigraphik 71: 195-198.

KRUmmReY, H. 1964: «Zum Plan einer neuen Sammlung der Carmina Latina epigraphican. Philologus 108: 304-310.

LommatzsCH, E. 1926: Carmina Latina Epigraphica. Supplementum. In aedibus B. G. Teubner. Leipzig.

López BARJA, P. 1993: Epigrafía latina. Las inscripciones romanas desde los orígenes al siglo III d. C. Tórculo. Santiago de Compostela.

López-MARTi, L. 1934: Santa Eulalia de Bóveda. Descripción y gráficos de monumento allí existente. Diputación Provincial. Lugo.

MARINER, S. 1960: "Loci similes virgilianos en epígrafes hispánicos de reciente aparición». Emerita 28/2: 317-326.

- 1969: "Presencia de la poesía clásica en la España antigua». Simposio sobre la Antigüedad clásica, Valle de los Caídos, 1-3 XI 1968. Sociedad Española de Estudios Clásicos. Madrid: 119-131.

- 1989: «La romanización lingüística en Hispania». Estudios sobre la Antigüedad en homenaje al profesor Santiago Montero Díaz. Universidad Complutense de Madrid. Madrid, 333-343.
Mazzolenl, D. et al. 2006: «lscrizioni di origine romana del Museo di Preistoria di Valenciam. Archivo de Prehistoria Levantina 26: 405-436.

MONTENEGRO RÚA, E. J. 2005: El descubrimiento y las actuaciones arqueológicas en Santa Eulalia de Bóveda (Lugo). Estudio historiográfico y documental de los avatares de un Bien de Interés Cultural. Concello de Lugo.

- 2008: «0 monumento de Santa Eulalia de Bóveda, sintese da súa historia coñecidan. En E. J. Montenegro Rúa et al.: Santa Eulalia de Bóveda. Xunta de Galicia. Santiago de Compostela: 11-40.

Rodriguez Colmenero, A. 2006: "A aparición do cristianismo no ámbito do convento xurídico lucense. Algúns testemuños». En F. Singul (ed.): San Froilán : Culto e Festa : [exposición en] Lugo, Catedral, Capela de San Froilán, Praza Ángel Fernández Gómez, 2006. Xunta de Galicia - Xacobeo. Santiago de Compostela: 46-69.

SANDERS, G. C. 1977: «Les inscriptions païennes et chrétiennes: symbiose ou métabolisme?». Revue de l'Université de Bruxelles 1: 44-64.

SusINI, G. C. 1982: Epigrafia romana. Jouvence. Roma.

VÁzouez SACO, F. 1958-1959: "Nuevas inscripciones romanas de la provincia de Lugon. Boletín de la Comisión Provincial de Monumentos Históricos y Artísticos de Lugo 49-52: 270-273.

VelÁzouEZ, I. 1996: «Dobletes en la epigrafía funeraria latina: materiales para su estudion. Cuadernos de Filología Clásica. Estudios Latinos 11: 77-113.

VEYNE, P. 1987: «El imperio romano». En P. Veyne (dir.): Historia de la vida privada. 1 - Del Imperio romano al año mil. Taurus. Madrid: 19-227. 